\title{
MODIFICATED EXTRACTION AND PURITY TEST OF ARENGA PINNATA GUM
}

\author{
JAMARAN KABAN ${ }^{1 *}$, JULIA REVENY², JULIATI TARIGAN ${ }^{1}$, NILSYA FEBRIKA ZEBUA ${ }^{2}$ \\ ${ }^{1}$ Department of Chemistry, Universitas Sumatera Utara, Medan, Indonesia. ${ }^{2}$ Department of Pharmacy, Universitas Sumatera Utara, Medan, \\ Indonesia. Email: jamarankaban@yahoo.com \\ Received: 25 October 2018, Revised and Accepted: 13 March 2018
}

ABSTRACT

Objective: The purpose of this study is modificated extraction method to obtain gum from Arenga pinnata Merr. and their purity test.

Methods: Gum has been extracted from palm seed using distilled water by centrifugation and warming. Characterization of gum was done by scanning electron microscopy-energy dispersivse X-ray and spectrophotometer infrared. Gum refluxed with $\mathrm{HCl} 2 \mathrm{~N}$ for $14 \mathrm{~h}$ would be the monomer. Galactose and mannose were used as standard. Purity test was done by the thin-layer chromatography (TLC) and Luff Schoorl method.

Results: The study results obtained that the modification methods (4.8\%) and centrifugation (4.6\%). Identification of functional groups with the spectrophotometer infrared provided the same spectrum forms between the two methods. Purity test by TLC with the best eluen butanol: ethanol:water $2: 2: 2$. Luff Schoorl's method gives results of $87.46 \%$, whereas the raw comparison galactose-mannose standard $96.69 \%$.

Conclusions: The modification method gives more results with the same purity rate as the centrifugation method.

Keywords: Galactomannan, Palm seed, Arenga pinnata, Modification, Extraction, Luff Schoorl.

(C) 2018 The Authors. Published by Innovare Academic Sciences Pvt Ltd. This is an open access article under the CC BY license (http://creativecommons. org/licenses/by/4. 0/) DOI: http://dx.doi.org/10.22159/ajpcr.2018.v11s1.26593

\section{INTRODUCTION}

Arenga pinnata is an Arecaceae family plant that grows in the tropics. A. pinnata is an enclosed seed plant because its fruit seed is wrapped with fruit flesh. The round-shaped palm fruit, about $4 \mathrm{~cm}$ in diameter, has three spaces and has three seeds, arranged in a chain-like string. Each bunch has 10 stalks or more, and each stalk has approximately 50 grains of green to yellowish brown. The young palm fruit is hard and firmly attached to the strands of the fruit, while the fruit is ripe fruit flesh is rather soft. The young fruit palm flesh contains very itchy mucus when it comes to the skin because it contains oxalic acid. Palm seeds are endosperm half-ripe palm fruit seeds after going through a process of soaking with lime water solution for several days so that it becomes soft, supple, and a bit clear white. A. pinnata gum is galactomannan compound [1].

Galactomannan is a polysaccharide not starch extracted from plant seeds by centrifuge method [2] and autoclaved [3] with water solvent at neutral $\mathrm{pH}$. Galactomannan is a carbohydrate reserve and regulates the amount of water in the seeds during germination [4]

The advantage of galactomannan when compared with other types of polysaccharides is its ability to form a thick solution in very low concentrations, and only slightly affected by $\mathrm{pH}$, ionic, and heating strength. The viscosity of galactomannan is very constant in the range of $\mathrm{pH}$ 1-10.5 which may be caused by its neutral molecular character. However, with high temperatures, and very acidic or alkaline conditions, galactomannan can be degraded [5].

Galactomannan has been widely applied in the food industry, pharmaceutical field, and cosmetics. In the food industry, galactomannan is commonly used as a clot in the ice cream industry to make ice not melt quickly in the cheese-making industry and salad spice. In the pharmaceutical industry, galactomannan was applied in the manufacture of tablets, hydrogels, films, and controlled release drug matrices [6].

The total carbohydrate analysis was done using the method of Luff Schoorl. International Commissions for Uniform Methods of Sugar Analysis considers Luff Schoorl's method as one of the methods used to standardize reducing sugar analysis. The entire compound carbohydrates are broken down into simple sugars (monosaccharides) with the help of the $\mathrm{HCl}$ acid and heat. Monosaccharide that is formed is then analyzed by Luff Schoorl's method. The method analysis principal is the reduction of $\mathrm{Cu}^{2+}$ to $\mathrm{Cu}^{+}$by becoming a monosaccharide. Free monosaccharides will reduce alkaline solution of metal salts or oxides form becomes free. The unreduced $\mathrm{Cu}^{2+}$ is then quantified by iodometric titration [7]

\section{METHODS}

The study was conducted of the Organic Chemistry Laboratory, Faculty of Mathematics and Natural Science, Universitas Sumatera Utara. The plant material used in this research is the palm seed which is determined by the Herbarium Medanense of Biology department. The materials used are ethanol, cupric sulfate, citric acid, sodium carbonate, hydrochloric acid, sodium hydroxide, sulfuric acid, potassium iodide, and sodium thiosulfate (Merck). The tools used are analytical balance (Sartorius), centrifuge (Hitachi), heating mantle (Seoh), and water bath. Palm seed gum was characterized by infrared spectrophotometer (Shimadzu) and scanning electron microscope-energy dispersive X-ray (EDX) spectroscopy (Bruker)

\section{Gum extraction}

As many as $500 \mathrm{~g}$ sample is cleaned and mashed with blender for \pm 3-5 min by the addition of water 1:10 and stored in the refrigerator for $24 \mathrm{~h}$, centrifuged at $9500 \mathrm{rpm}$ for $15 \mathrm{~min}$. Supernatant liquid added ethanol $96 \%$ in comparison with the volume of $1: 2$, then stored in the refrigerator for $24 \mathrm{~h}$. Filtered sediment formed, then washed with ethanol p.a. Sediment was dried in the desiccators $[1,2]$.

\section{Modification method}

As many as $500 \mathrm{~g}$ is stored in the refrigerator for $24 \mathrm{~h}$, then the sample is cleaned and mashed with blender for $\pm 3-5 \mathrm{~min}$ by the addition of water 1:1 and warmed $5 \mathrm{~min}$ in water bath, and then stored in the refrigerator for $24 \mathrm{~h}$. Supernatant obtained is stored in the refrigerator for $24 \mathrm{~h}$, then added ethanol $96 \%$ in comparison with the $1: 2$ and then stored in the refrigerator for $24 \mathrm{~h}$. Filtered sediment formed, then washed with ethanol p.a. Sediment was dried in the desiccator [3]. 
Thin-layer chromatography

About $50 \mathrm{~g}$ of palm seed gum was hydrolyzed by addition of $50 \mathrm{~mL} 1 \mathrm{~N}$ $\mathrm{HCl}$ using a heating mantle for $14 \mathrm{~h}$, then the solution neutralized with the addition of sodium carbonate, the filtrate evaporated into viscous fluid. Then, a small amount of each aliquot is bottled on Whatman No.1 paper with micropipette. Then, eluted with butanol: ethanol:water (BEW) 4:1:1, 1:4:3, 1:3:4, 1:4:4, and 2:2:2, butanol: acetic acid: water $4: 1: 5,20 \%$ and $50 \%$ acetic acid and $10 \%$ and $20 \%$ hydrochloric acid. Then, it was dried and detected by spray reagent $(1.2 \mathrm{~g} \mathrm{p}$-anisidine and $1.6 \mathrm{~g}$ phthalate acid in $100 \mathrm{ml}$ ethanol) will give a brown color [8].

\section{Luff Schoorl's analysis}

Luff Schoorl solution is made by $25 \mathrm{~g}$ cupric sulfate dissolved in $100 \mathrm{~mL}$ water, $50 \mathrm{~g}$ of citric acid dissolved in $50 \mathrm{~mL}$ water, and $388 \mathrm{~g}$ sodium carbonate dissolved in $400 \mathrm{~mL}$ water free carbon dioxide. A solution of citric acid sodium carbonate in solution is poured while stirring carefully next added cupric sulfate and added water to $1000 \mathrm{~mL}$.

About $100 \mathrm{mg}$ palm seed gum hydrolyzed with $100 \mathrm{~mL} 1 \mathrm{~N} \mathrm{HCl}$ for $14 \mathrm{~h}$ using a heating mantle, then neutralized with $\mathrm{NaOH} 30 \%$, then put in flask $100 \mathrm{~mL}$ and sufficient volume with distilled water. Then, plucked $10 \mathrm{~mL}$ and added with $10 \mathrm{~mL}$ of Luff Schoorl solution quantitatively and $6 \mathrm{~mL}$ of distilled water, added some boiling stones and then heated to boiling for $10 \mathrm{~min}$ in a water bath, then cooled immediately with ice. After a cold, $10 \mathrm{~mL}$ of sulfuric acid $25 \%$ is added and $6 \mathrm{~mL}$ of potassium iodide $30 \%$, it is immediately titrated with a standard solution of $0.1 \mathrm{~N}$ sodium thiosulfate until a weak yellow color is formed. Then, $3 \mathrm{~mL}$ of $0.5 \%$ starch indicator until the solution was blue, and the titration was resumed until blue color disappeared, recorded the titration volume used. The same experiment was performed on blanks by substituting the sample solution with water. Next is calculated by the formula below [7]

$$
\mathrm{V} \mathrm{Na}_{2} \mathrm{~S}_{2} \mathrm{O}_{3}=\frac{(\mathrm{mL} \text { blanko-mL sample }) \times \mathrm{N} \mathrm{Na}_{2} \mathrm{~S}_{2} \mathrm{O}_{3}}{0.1}
$$

After getting the value of $\mathrm{V} \mathrm{Na} \mathrm{S}_{2} \mathrm{O}_{3}$ then equalized the value on Luff schoorl's table to get the value of $\mathrm{Z}$.

$$
\text { Total sugar content }(\%)=\frac{\mathrm{Z} \times \mathrm{DF} \times 0.95}{\text { Sample weight }(\mathrm{mg})} \times 100 \%
$$

$\mathrm{Z}$ is seen in Luff Schoorl's table to see the sugar content and DF is dilution factor.

\section{RESULTS}

The study results obtained that the modification methods (4.8\%) and centrifugation (4.6\%). Fig. 1 shows the functional group identification with the infrared spectrophotometer giving a very similar spectrum between the centrifuge and the modification method, it proves that both are galactomannan compounds. Fig. 2a shows the surface morphology of a hollow Arenga pinnata gum particle using Scanning electron microscopy (SEM), and Fig.2b shows the elements contained in the gum using Energy Dispersive X-ray Spectroscopy (EDS) are atoms C and O. Fig. 3 show the purity test by TLC with the best eluen butanol: ethanol:water 2:2:2. Table 1 show the Luff Schoorl's method gives results of $87.46 \%$, whereas the raw comparison galactose-mannose standard $96.69 \%$.

\section{DISCUSSION}

Infrared gum spectrum of centrifuge seed method is shown in Fig. 1a where the wave number at $3425.58 \mathrm{~cm}^{-1}$ shows the stretching vibration -OH. The wave number at $2924.09 \mathrm{~cm}^{-1}$ shows an aliphatic $\mathrm{C}-\mathrm{H}$ stretching vibration supported by wave numbers at 1404.18 and $1319.3 \mathrm{~cm}^{-1}$ indicating the presence of an aliphatic C-H bending vibration. Wave numbers at 1635.64 and $1087.85 \mathrm{~cm}^{-1}$ indicate the presence of bending vibrations $\mathrm{C}-\mathrm{O}$ in $\mathrm{C}-\mathrm{OH}$ bonds.

The infrared spectrum of modified palm seed gum is shown in Fig. $1 \mathrm{~b}$ where the wave number at $3394.72 \mathrm{~cm}^{-1}$ shows the stretching vibration $-\mathrm{OH}$. The wave number at $2924.09 \mathrm{~cm}^{-1}$ shows the stretching vibration of $\mathrm{C}-\mathrm{H}$ alifatis supported by the wave numbers at 1373.32 and $1311.59 \mathrm{~cm}^{-1}$ indicating the existence of an aliphatic C-H bending vibration. Wave numbers at 1639.49 and $1026.13 \mathrm{~cm}^{-1}$ indicate the presence of bending vibrations $\mathrm{C}-\mathrm{O}$ in $\mathrm{C}-\mathrm{OH}$ bonds.

Wavenumber at $2800-3000 \mathrm{~cm}^{-1}$ shows vibration stretching $\mathrm{C}-\mathrm{H}$ and $3100-3500 \mathrm{~cm}^{-1}$ shows vibration stretching $\mathrm{O}-\mathrm{H}$. The wide peak at $1134-983 \mathrm{~cm}^{-1}$ is a bending characteristic of $\mathrm{C}-\mathrm{OH}$. The peak at $1635 \mathrm{~cm}^{-1}$ indicates a bond between the polysaccharide and water [9].

Fig. 1a and b show the identical infrared spectrum shape, especially in the fingerprint region $\left(2000-500 \mathrm{~cm}^{-1}\right)$. This infrared spectrum shows galactomannan compounds such as the infrared guar gum spectrum. Guar gum is composed of a mixture of galactose and mannose combined through a glucoside link, which can be described chemically as galactomannan. Galactomannan polysaccharides have a linear general structure, in which the polymer unit $(1,4)-\beta$-D-mannopyranose, bonded to $(1,6)-\alpha$-D-galactopyranose [4].

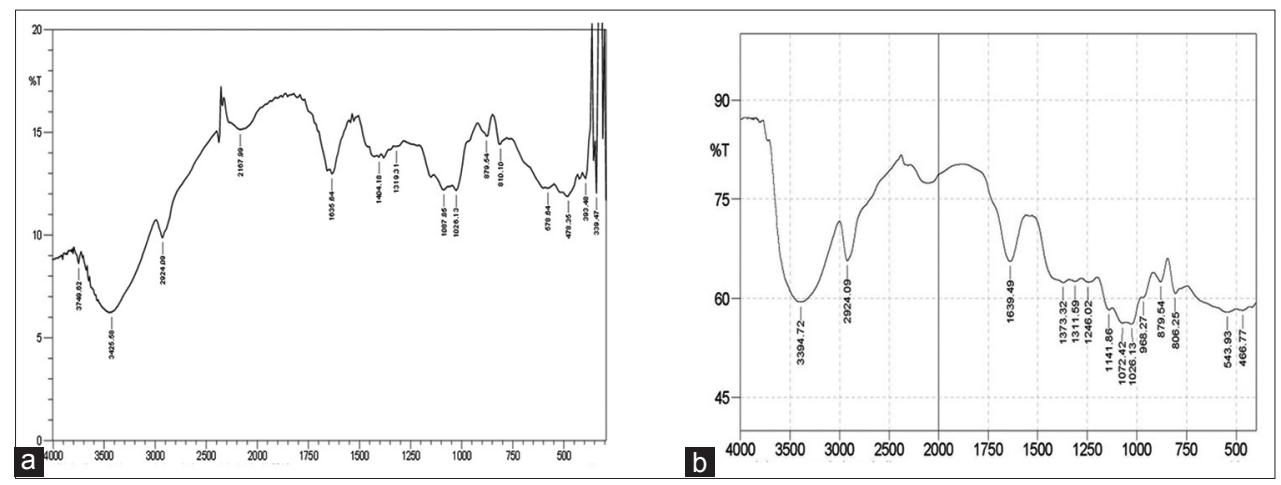

Fig. 1: Palm seed gum by (a) centrifuge method, (b) modification method

Table 1: Data on total sugar content analysis of arenga pinnata gum with Luff schoorl's method

\begin{tabular}{llllllll}
\hline Average & Sample weight & Titration volume & $\boldsymbol{\Delta}$ & $\mathbf{Z ~ ( m g )}$ & $\mathbf{D F}$ & $\mathbf{N a}_{2} \mathbf{S}_{\mathbf{2}} \mathbf{O}_{\mathbf{3}}$ (N) & Total sugar (\%) \\
\hline Blanko volume & - & $9.60 \mathrm{~mL}$ & & & & 0.0987 & - \\
Sample volume & $101.4 \mathrm{mg}$ & $5.70 \mathrm{~mL}$ & $3.90 \mathrm{~mL}$ & 9.335 & 10 & & 87.46 \\
Standard volume & $102.3 \mathrm{mg}$ & $5.25 \mathrm{~mL}$ & $4.35 \mathrm{~mL}$ & 10.412 & 10 & & 96.69 \\
\hline
\end{tabular}



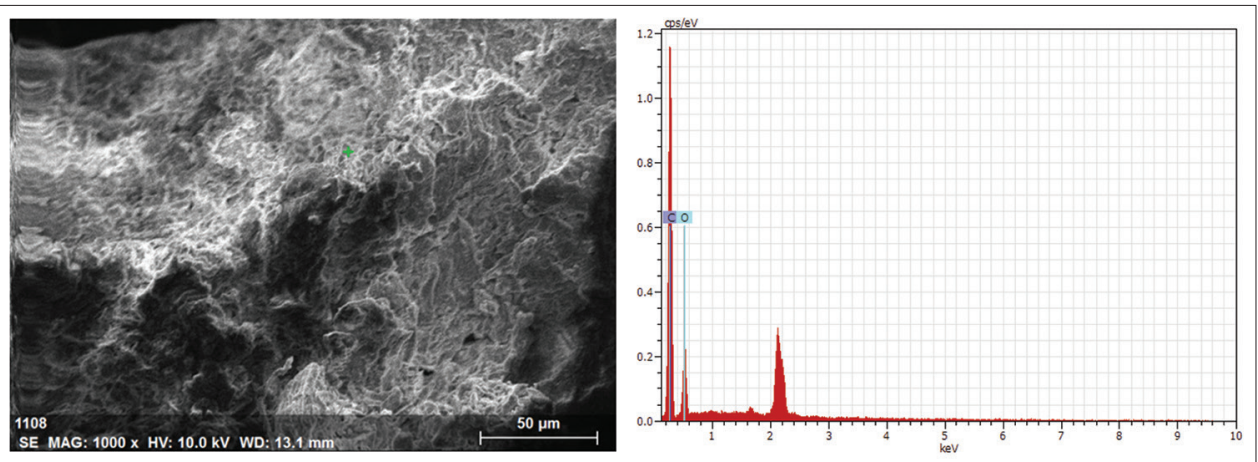

Fig. 2: (a) Scanning electron microscopy, (b) energy dispersive X-ray of palm seed gum by modification method
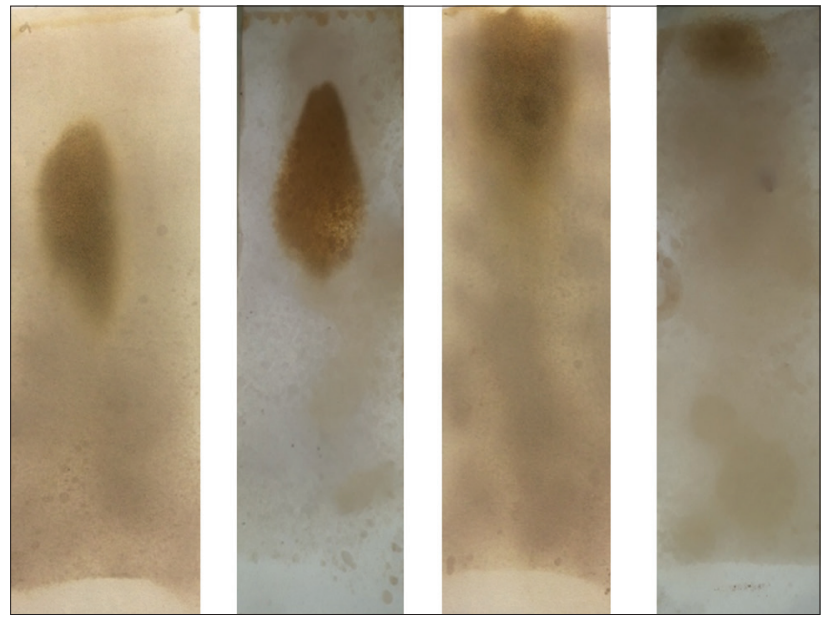

Fig. 3 : Thin-layer chromatography of palm seed gum by butanol:ethanol:water (2:2:2). (a) galactose standard,

(b) mannose standard, (c) galactose + mannose, (d) palm seed gum after refluxed

Fig. 2a shows the particles morphology of palm seed gum by scanning electron microscopy (SEM). Fig. $2 \mathrm{~b}$ shows the elements contained in the palm seeds gum are $71.47 \% \mathrm{C}$ atoms and $28.53 \%$ $\mathrm{O}$ atoms by EDX spectroscopy. Hollow particle surfaces allow these compounds to still be cross-linked with crosslinking agents. SEMEDX is able to show the particle surface shape and elements found on the particles [1].

Gum has been refluxed with the addition of $1 \mathrm{~N} \mathrm{HCl}$ for $14 \mathrm{~h}$, then bottled on paper chromatography performed to separate the galactose-mannose contained in the sample. Of all motion phase comparisons, BEW 2:2:2 is the best phase of motion where the stain is formed away from the bottling point. However, with all comparisons of the phase of motion, it has not been able to separate galactosemannose in sample and standard. Rf obtained after being eluted with BEW 2:2:2 phase of the galactose comparator $0.65 \mathrm{~cm}$ and mannose $0.63 \mathrm{~cm}$. The adjacent $\mathrm{Rf}$ ensures that the galactose cannot be determined by comparison with the paper chromatography method. However, elution of BEW 2:2:2 ensure that galactomannan of palm seed has been purified [8].

Sugar levels in the sugar palm seed gum successfully established by Luff Schoorl method. In principle by hydrolyzing galactomannan from Arenga pinnata will produce monosaccharide compounds that have the properties of reducing. The Luff Schoorl solution is added in excess so that cupric sulfate $\left(\mathrm{Cu}^{2+}\right)$ is reduced to $\mathrm{Cu}^{+}$by reducing sugars. Excess $\mathrm{Cu}^{2+}$ can oxidize potassium iodide $(\mathrm{I})$ to iodine $\left(\mathrm{I}_{2}\right)$. Iodine is titrated with a standard solution of sodium thiosulfate. Iodine is equivalent to $\mathrm{Cu}^{2+}$ excess so that the sugar content is the reduction of the titration volume of the blank less the titration of the sample. The total sugar content of sugar palm seed gum was $87.46 \%$ while galactose+mannose was $96.69 \%$. The difference in levels is due to the need for optimization of glycosidic bond termination time on palm seed gum [7].

\section{CONCLUSIONS}

The modification method gives more results with the same purity rate as the centrifugation method. The shape of the infrared spectrum is similar between the centrifuge method and the heating method. Luff Schoorl's method can analyze total carbohydrate levels. Optimization of reflux needs to be done to ensure the galactomannan compound has disconnected its galactose and mannose.

\section{ACKNOWLEDGMENT}

Thank you for funding support by the Research Institute University of Sumatera Utara on the TALENTA PUU 2017 scheme.

\section{AUTHOR'S CONTRIBUTION}

Study conception: Tarigan.

Acquisition of data: Reveny.

Analysis of data: Zebua.

Drafting of manuscript: Zebua.

Critical revision: Kaban.

\section{CONFLICTS OF INTEREST}

All authors have none to declare.

\section{REFERENCES}

1. Tarigan J, Purba J. The characterization of phosphate crosslinked galactomannan "kolang kaling" polysaccharide. Majalah Polim Indones 2015;18:1-8

2. Kooiman P. Structures of the galactomannans from seeds of Annona muricata, Arenga saccharifera, Cocos nucifera, Convolvulus tricolor, and Sophora japonica. Carbohydr Res 1971;20:329-37.

3. Tamaki Y, Teruya T, Tako M. The chemical structure of galactomannan isolated from seed of Delonix regia. J Biosci Biotechnol Biochem 2010;74:1110-2.

4. Mathur V, Mathur NK. Fenugreek and other lesser known legume galactomannan-polysaccharides: Scope for developments. J Sci Ind Res 2005;64:475-81.

5. Cerqueira MA, Bourbon AI, Pinheiro AC, Martins JT, Souza BW, Teixeria AJ, et al. Galactomannans Use in the development of the edible films/coatings for food applications. Food Sci Technol 2011;22:662-71.

6. Kabir GI, Yagen B, Penhasi A, Rubinstein A. Low swelling, crosslinked guar and its potential use as colon-specific drug carrier. Pharm Res 1998:15:1019-25.

7. Suryaningsiha NL, Pasaribu YP. Dewaka banana as an alternative energy source. Procedia Food Sci 2015;3:211-5.

8. Veerappa HM, Sirigeri JP. Investigating plant galactomannans. Biochem Mol Biol Educ 2002;30:101-3.

9. Silverstein RM, Bassler GG, Morrill TC. Spectrometric Identification of Organic Compounds. $7^{\text {th }}$ ed. New York: John Wiley \&Sons; 2005. 